Article

\title{
Current Source AC-Side Clamped Inverter for Leakage Current Reduction in Grid-Connected PV System
}

\author{
Xiangli Li, Na Wang, Guocheng San and Xiaoqiang Guo * \\ Department of Electrical Engineering, Yanshan University, Qinhuangdao 066004, China; 1xl@ysu.edu.cn (X.L.); \\ 18712728609@163.com (N.W.); hbsgc@163.com (G.S.) \\ * Correspondence: gxq@ysu.edu.cn; Tel.: +86-13785070194
}

Received: 16 October 2019; Accepted: 29 October 2019; Published: 6 November 2019

check for updates

\begin{abstract}
For the grid-connected photovoltaic inverters, the switching-frequency common-mode voltage brings the leakage current, which should be eliminated. So far, many kinds of single-phase inverters have been published for this purpose, but most of them are the conventional voltage-type ones, which have the disadvantages of poor reliability due to the DC-link electrolytic capacitor and the risk of short-through of the bridge switches. To solve this technical issue, a novel current source inverter with AC-side clamping is proposed to mitigate the switching-frequency common-mode voltage. Meanwhile, a novel modulation method is proposed for the new single-phase inverter to achieve low-frequency operation of the main switches, which reduces the switching losses. Finally, the proposed method is implemented on the TMS320F28335DSP + XC6SLX9FPGA digital hardware platform. Also, the performance comparisons are done with the traditional solution. The results prove the proposed solution.
\end{abstract}

Keywords: current source inverter; common-mode voltage; leakage current

\section{Introduction}

Photovoltaic (PV) power generation is one of the ways to effectively use energy. Through photovoltaic panels to obtain energy, photovoltaic systems can provide green sustainable solutions $[1,2]$. In general, energy can be obtained from photovoltaic panels by grid connection of photovoltaic inverters or by connecting transformers. However, the transformer is relatively heavy, sizable, and costly, with undesirable power loss problems. Therefore, the transformerless PV inverters are promising and attractive in industrial and academic fields [3-7]. However, when the transformerless PV inverter is connected to the grid, there are still many technical challenges to be solved, such as the leakage current or ground current. Without the transformer isolation, the electrical connection exists between the photovoltaic panel and the grid, and a leakage current will be generated on the parasitic capacitance between the photovoltaic panel and the ground. Leakage currents can adversely affect grid current, personal safety and electro-magnetic interference issues. So, the German standard VDE 0126-1-1 defines that the PV system should be off from the grid when the leakage current exceeds $300 \mathrm{~mA}$.

To solve the above problems, many kinds of topologies have been published, such as Heric, $\mathrm{H} 6$, oH5, H5 [8-11]. In theory, a constant common-mode voltage would be achieved with the above topologies. In fact, due to the influence of the switch junction capacitance, the switching common-mode voltage changes with high frequency. Consequently, the leakage current cannot be completely eliminated. Nevertheless, most topologies are proposed from the perspective of voltage-type inverters. In a voltage source inverter, the DC-side electrolytic capacitor reduces the reliability and life of the inverter system. Moreover, the voltage source inverter has a risk of short-through, which leads to 
the reliability issue. In addition, the current source inverter has a unique short-circuit operation capability, which improves the reliability of the system. Aside from that, the DC-link of the current source inverter uses an inductor instead of an electrolytic capacitor, which can be designed to work at high temperatures [12-15]. The current-type inverters, as a matter of fact, have been applied in photovoltaic systems over the past few decades [16-22].

However, due to the switching-frequency common-mode voltage, the leakage current of the conventional current-source four-switch inverter is large. This characteristic limits the application of conventional current source inverters in transformerless photovoltaic systems. Inspired by the bypass-type voltage source inverter topology [23], this paper proposes a novel AC-side clamped current-source inverter topology, which effectively suppresses the switching-frequency common-mode voltage, so as to reduce the leakage current. At the same time, for the new inverter, a new modulation for reducing the switching loss is proposed. In addition, the proposal is proven by the experiment results.

\section{Traditional Current Source Inverter}

Figure 1 is a schematic of the conventional current-source inverter circuit. Where, $L_{d c 1}$ and $L_{d c 2}$ are DC-side inductors, $S_{1}-S_{4}$ are IGBTs (Insulated Gate Bipolar Transistor), $C_{f}$ is the AC-side filter capacitor, $v_{g}$ is the AC-side voltage, and $C_{P V}$ is the parasitic capacitance between the PV array and the ground. The voltage change across the parasitic capacitance $C_{P V}$ will cause a leakage current, which will affect the grid current.

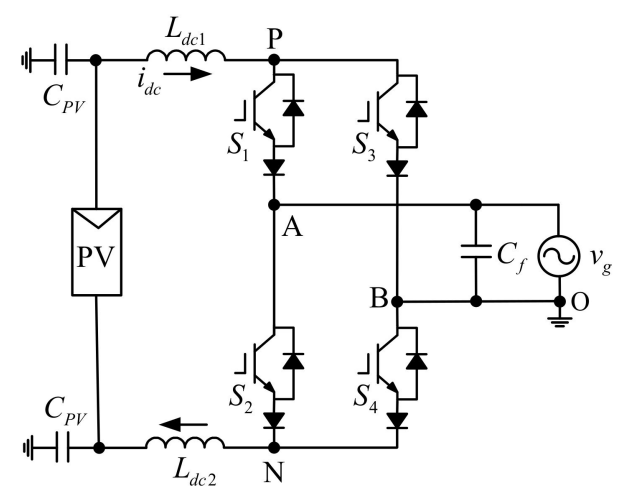

Figure 1. Conventional current-source inverter.

In order to understand the factors affecting the leakage current, a common-mode loop model, as shown in Figure 2, is established. Where, $V_{C M}$ represents the common-mode voltage (CMV), and $Z$ is the equivalent impedance of the common-mode loop.

$$
\begin{gathered}
V_{C M}=\frac{V_{P O}+V_{N O}}{2} \\
Z=\frac{s L_{d c 1} L_{d c 2}}{L_{d c 1}+L_{d c 2}} \\
i_{\text {leakage }}=2 C_{P V} \frac{d V_{C P V}}{d t} \\
V_{C P V}=\frac{1}{2 s C_{P V} Z+1} V_{C M}
\end{gathered}
$$

where, $V_{C P V}$ represents the voltage across the parasitic capacitance $2 C_{P V}$. According to Equations (3) and (4),

$$
I_{\text {leakage }}(s)=\frac{2 s C_{P V}}{2 s C_{P V} Z+1} V_{C M}
$$




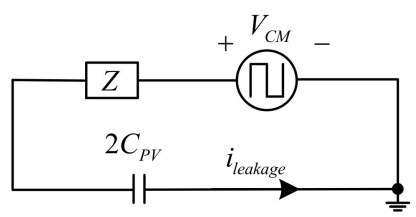

Figure 2. Common-mode model.

According to Equation (2) and Equations (3)-(5), the leakage current $I_{\text {leakage }}$ is dependent on the equivalent common-mode impedance and the rate of the common-mode voltage change. Therefore, reducing the leakage current can be considered from two points, one is to increase the common-mode loop impedance, and the other is to reduce the rate of the common-mode voltage change or to maintain the common-mode voltage constant.

Conventional current-source inverters have four switching states, as shown in Table 1. As shown in Figure 3, the driving signal waveforms of $S_{1}$ and $S_{3}$ are changed by low frequency, and the driving signals of $S_{2}$ and $S_{4}$ are changed at a high frequency.

Table 1. Current space vectors, switching states and common-mode voltage (CMV).

\begin{tabular}{|c|c|c|c|c|c|}
\hline \multirow[t]{2}{*}{ Current Vectors } & \multicolumn{4}{|c|}{ Switching States } & \multirow[t]{2}{*}{ CMV } \\
\hline & $S_{1}$ & $S_{2}$ & $S_{3}$ & $S_{4}$ & \\
\hline$I_{1}$ & 1 & 0 & 0 & 1 & $0.5 v_{g}$ \\
\hline$I_{2}$ & 1 & 1 & 0 & 0 & $v_{g}{ }^{\circ}$ \\
\hline$I_{3}$ & 0 & 1 & 1 & 0 & $0.5 v_{g}$ \\
\hline$I_{4}$ & 0 & 0 & 1 & 1 & 0 \\
\hline
\end{tabular}

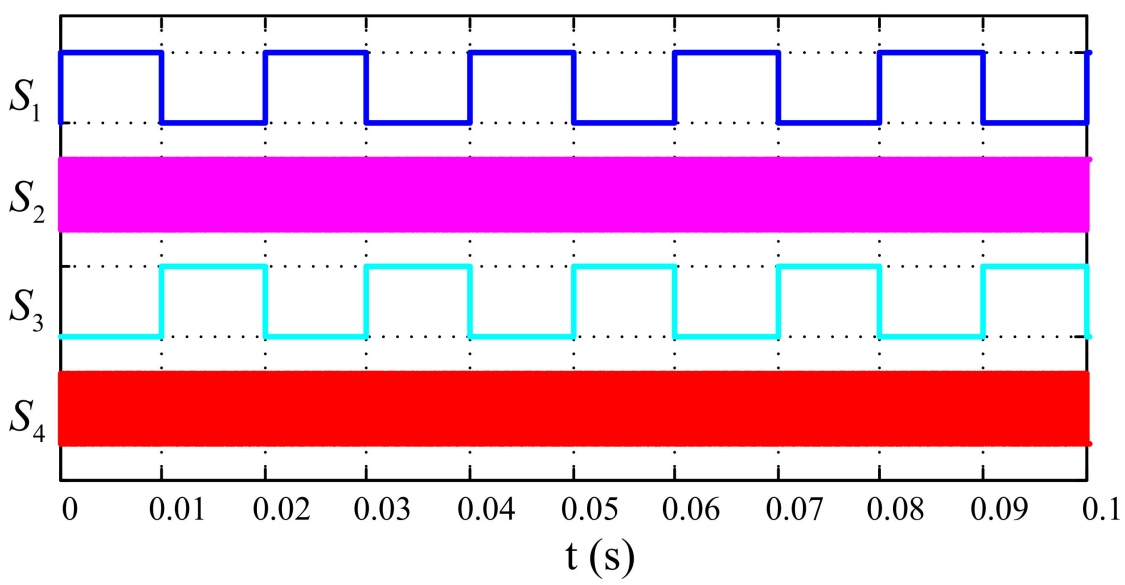

Figure 3. Gating signals of current-source inverter.

As switch $S_{1}$ and the switch $S_{4}$ are turned on, the common-mode voltage can be derived according to Equation (1):

$$
V_{C M}=\frac{V_{P O}+V_{N O}}{2}=\frac{V_{A O}+V_{B O}}{2}=\frac{v_{g}}{2}
$$

where, $V_{P O}$ represents the potential of $\mathrm{P}$ with respect to $\mathrm{O}$, and $V_{N O}$ represents the potential of $\mathrm{N}$ with respect to $\mathrm{O}$.

When the switch $S_{1}$ and the switch $S_{2}$ are turned on, the common-mode voltage is:

$$
V_{C M}=\frac{V_{P O}+V_{N O}}{2}=V_{A O}=v_{g}
$$


As the switch $S_{2}$ and the switch $S_{3}$ are turned on, the common-mode voltage is:

$$
V_{C M}=\frac{V_{P O}+V_{N O}}{2}=\frac{V_{B O}+V_{A O}}{2}=\frac{v_{g}}{2}
$$

When the switch $S_{3}$ and the switch $S_{4}$ are turned on, the common mode voltage is:

$$
V_{C M}=\frac{V_{P O}+V_{N O}}{2}=V_{B O}=0
$$

In summary, the switching-frequency common-mode voltage in the system leads to serious leakage current problems of the current-type inverter. In order to effectively suppress the leakage current, this paper will propose a new topology in the next section, which can eliminate the switching common-mode voltage variation for the leakage current attenuation.

\section{New Current-Source Inverter}

This section introduces a new current-source inverter topology that can eliminate high-frequency common-mode voltage variation from a topological perspective. As shown in Figure 4, a voltage source DC-bypass inverter is proposed in Reference [23]. It uses the diode to clamp the unchancommon-mode voltage unchanged at $V_{d c} / 2$, and thus, the leakage current can be suppressed. The corresponding current-type topology is obtained, as illustrated in Figure 5.

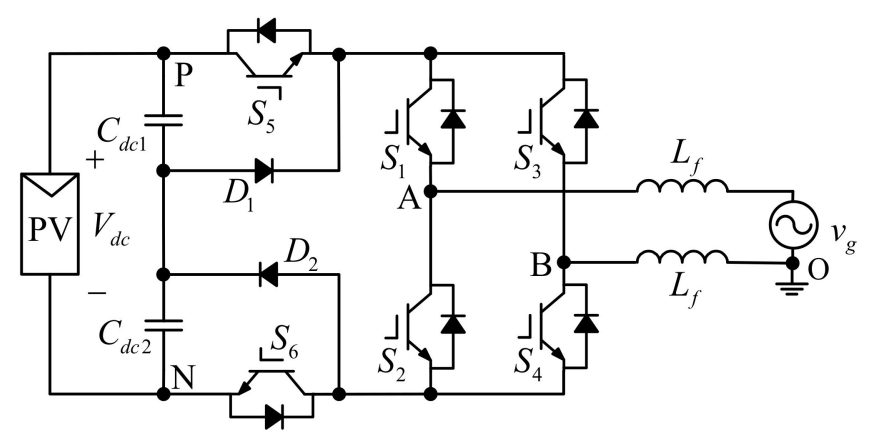

Figure 4. Voltage source inverter with DC-side clamping.

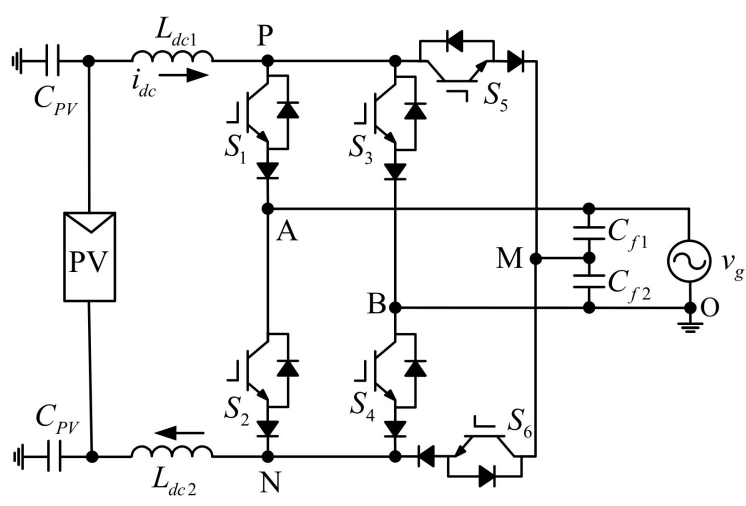

Figure 5. New current-source inverter with AC-side clamping.

According to Table 1, the common-mode voltage depends on the grid voltage, and the common-mode voltage variation is from 0 to $v_{g}$. For eliminating the high-frequency common-mode voltage, the DC-side positive bus $\mathrm{P}$ and the negative bus $\mathrm{N}$ are clamped at the midpoint of the AC-side filter capacitors during the freewheeling period. According to Equation (1), the common-mode voltage is $v_{g} / 2$ in the freewheeling cycle.

$$
V_{C M}=\frac{V_{P O}+V_{N O}}{2}=\frac{v_{g}}{2}
$$


During the freewheeling period, the switch $S_{5}$ and the switch $S_{6}$ are on to establish a freewheeling path for the DC-side current. The switching states in the active state are the same as that of the conventional current-source inverter. During the half-positive cycle, the switch $S_{1}$ and the switch $S_{4}$ are turned on. In the half-negative cycle, the switch $S_{2}$ and the switch $S_{3}$ are on. The new current-source inverter switching states and corresponding common-mode voltages are given in Table 2.

Table 2. Current space vectors, switch states and CMV.

\begin{tabular}{|c|c|c|c|c|c|c|c|}
\hline \multirow[t]{2}{*}{ Current Vectors } & \multicolumn{6}{|c|}{ Switching States } & \multirow[t]{2}{*}{ CMV } \\
\hline & $S_{1}$ & $S_{2}$ & $S_{3}$ & $S_{4}$ & $S_{5}$ & $S_{6}$ & \\
\hline$I_{1}$ & 1 & 0 & 0 & 1 & 0 & 0 & $0.5 v_{g}$ \\
\hline$I_{3}$ & 0 & 1 & 1 & 0 & 0 & 0 & $0.5 v_{g}^{\circ}$ \\
\hline$I_{0}$ & 0 & 0 & 0 & 0 & 1 & 1 & $0.5 v_{g}^{\delta}$ \\
\hline
\end{tabular}

It can be seen from Table 2 that the new current-source inverter has three switching states, and the common-mode voltages corresponding to each switching state are the same, which are $0.5 v_{g}$, and the common-mode voltage frequency is consistent with the fundamental frequency. Since the frequency of the grid voltage $v_{g}$ is smaller than the high switching frequency, the influence of the fundamental-frequency voltage on the switching frequency common-mode characteristics can be ignored. According to Equations (3)-(5), the proposed method eliminates the switching frequency common-mode voltage variation, so that the leakage current is effectively suppressed.

The driving signal waveform of the proposed inverter is shown in Figure 6 . The switches $S_{1}-S_{6}$ are high-frequency changes and the switching loss is increased. To solve this problem, a novel modulation method for reducing the switching loss based on the characteristics of the new topology is proposed. Taking the half-positive cycle operating state as an example, the active state $I_{1}$ and the zero state $I_{0}$ alternately operate. Figures 7 and 8 are circuit diagrams of the system operating in the active state $I_{1}$ and the zero state $I_{0}$, respectively.

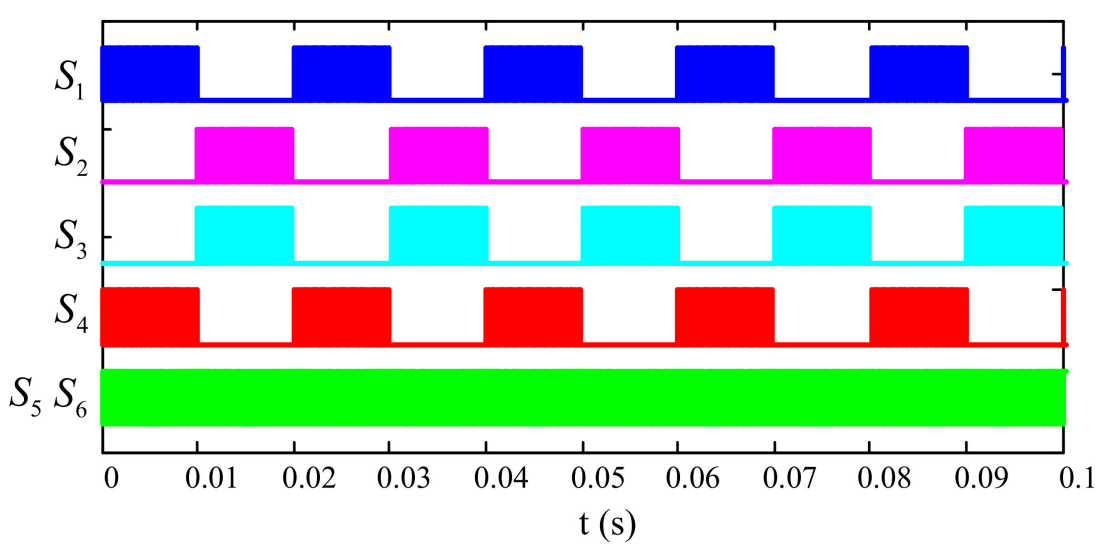

Figure 6. Gating signal of new current-source inverter. 


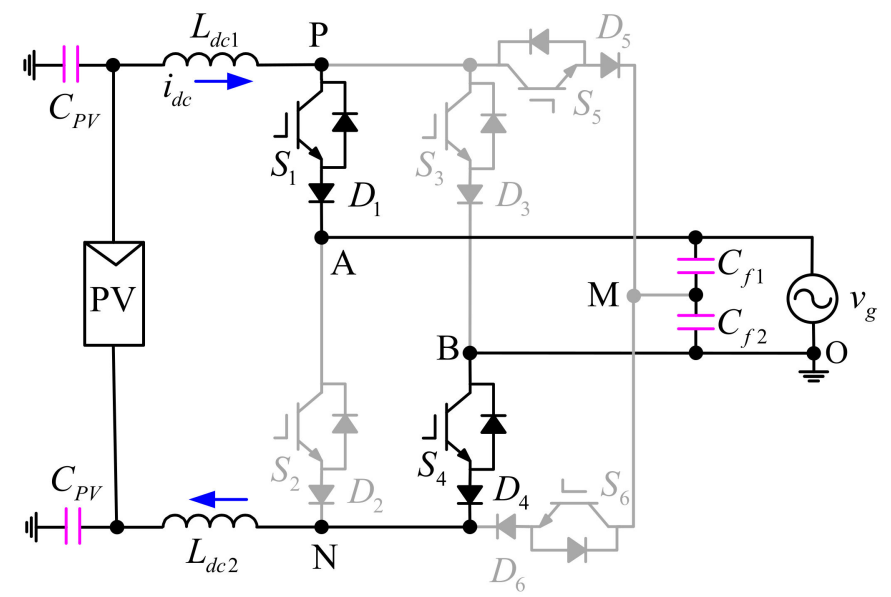

Figure 7. Schematic of the active state $I_{1}$.

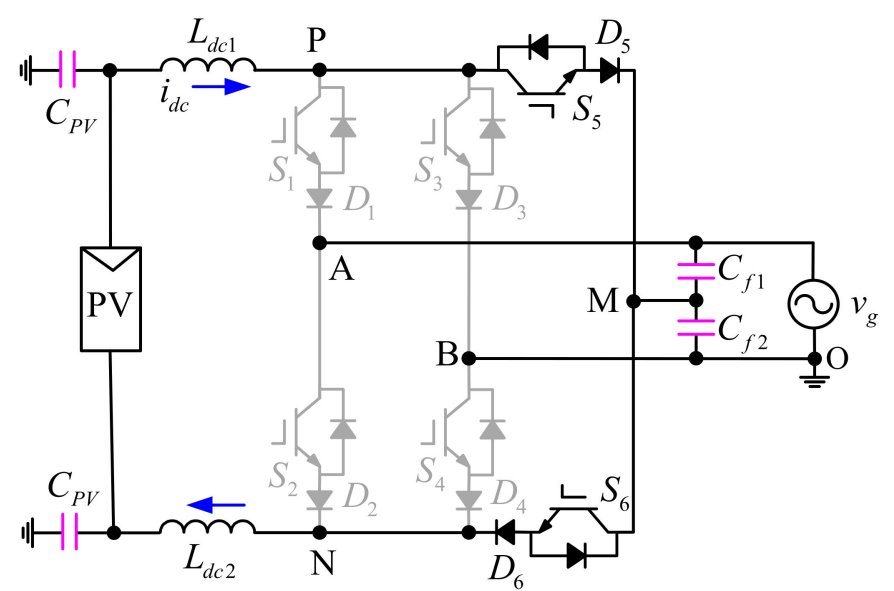

Figure 8. Schematic with the active state $I_{0}$.

According to Figure 8, when the system operates in the zero state, the potential at point $\mathrm{A}$ is $v_{g}$, the potential at point $B$ is 0 , the point $P$ and the point $N$ are clamped at point $M$, and the potential at point $\mathrm{M}$ is $v_{g} / 2$. Therefore, in the zero state, if the switch $S_{1}$ and the switch $S_{4}$ are in the on state, the diodes $D_{1}$ and $D_{4}$ are reversely turned off, and the upper arm and the lower arm are still in the off state, and the circuit is as shown in Figure 9. The switch $S_{1}$ and the switch $S_{4}$ can always be in the on state during the half-positive cycle. In a similar manner, for the half-negative cycle, the switch $S_{2}$ and the switch $S_{3}$ can always be in the on state. The switching states of the new modulation method can be obtained, as shown in Table 3. Figure 10 shows the gating signals' waveform when using the new modulation method. It can be seen that the switches $S_{1}-S_{4}$ vary by low frequency, and the switching loss is reduced. 


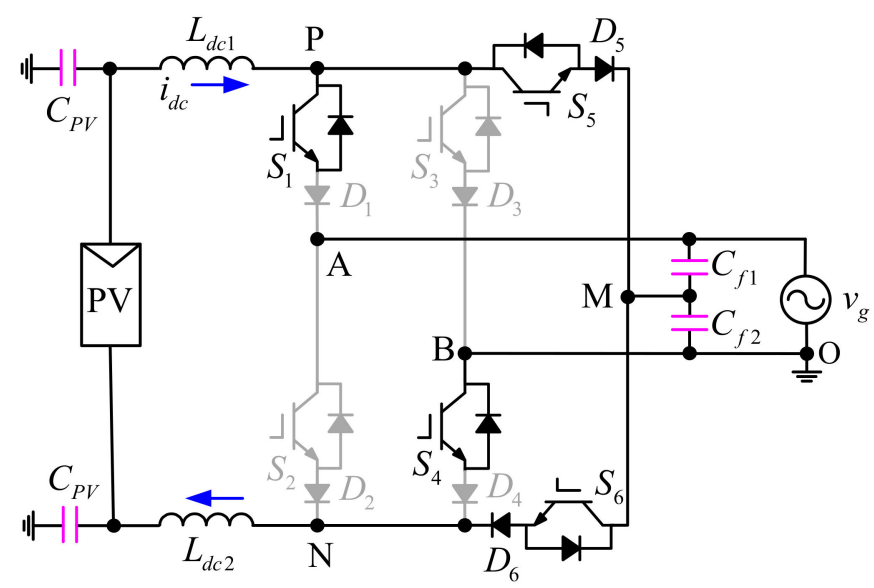

Figure 9. Schematic under new modulation method.

Table 3. Current space vectors, switching states and CMV.

\begin{tabular}{cccccccc}
\hline Current Vectors & \multicolumn{7}{c}{ Switching States } \\
\hline & $S_{1}$ & $S_{2}$ & $S_{3}$ & $S_{4}$ & $S_{5}$ & $S_{6}$ & \\
$I_{1}$ & 1 & 0 & 0 & 1 & 0 & 0 & $0.5 v_{g}$ \\
$I_{01}$ & 1 & 0 & 0 & 1 & 1 & 1 & $0.5 v_{g}$ \\
$I_{3}$ & 0 & 1 & 1 & 0 & 0 & 0 & $0.5 v_{g}$ \\
$I_{03}$ & 0 & 1 & 1 & 0 & 1 & 1 & $0.5 v_{g}$ \\
\hline
\end{tabular}

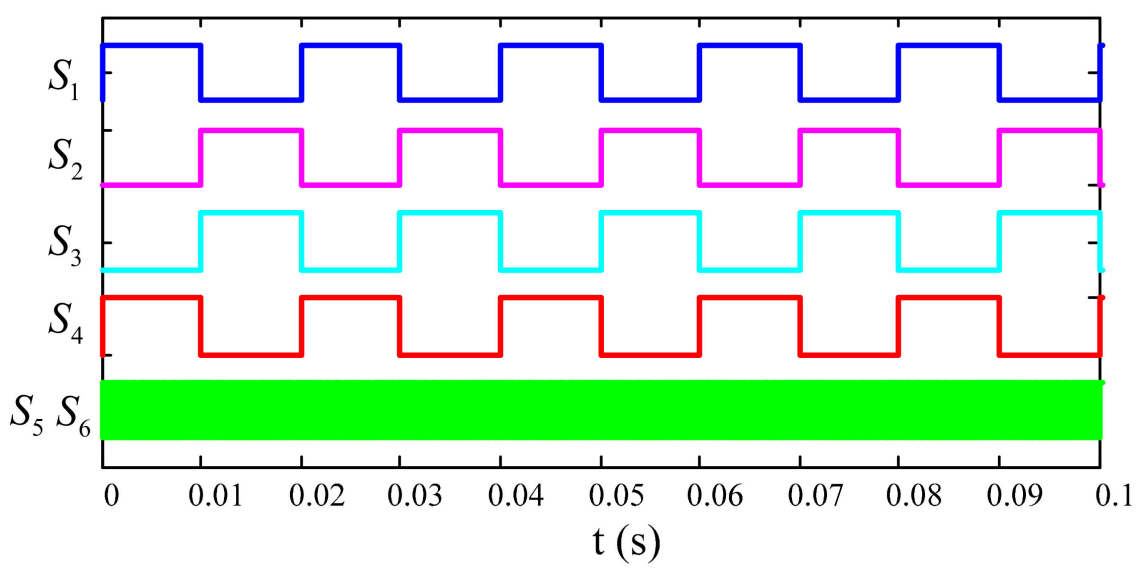

Figure 10. Gating signals with the new modulation.

\section{Results}

In this section, a system experiment setup was built, and the proposal was compared against the traditional method. The algorithm is realized by the DSP (TMS320F28335) and FPGA (Xilinx XC6SLX9). The experimental parameters are shown in Table 4. Figure 11 shows the control diagram of the proposal. The phase angle $\theta$ is detected to generate the reference current. The output $m$ of the PR (Proportional Resonant) regulator is used as the input of the new modulation method. The new modulation method judges the positive or negative of $m$ and selects the corresponding switching sequence. The specific switching sequence selection is shown in Figure 12, where $T_{s}$ represents the switching period. 
Table 4. Experimental parameters.

\begin{tabular}{cc}
\hline Parameters & Values \\
\hline Switching frequency & $10 \mathrm{kHz}$ \\
AC-side filter capacitors $\left(C_{f 1} C_{f 2}\right)$ & $18.8 \mu \mathrm{F}$ \\
DC-side inductances $\left(L_{d c 1} L_{d c 2}\right)$ & $5 \mathrm{mH}$ \\
Parasitic capacitance $\left(C_{p v}\right)$ & $75 \mathrm{nF}$ \\
DC-side current & $8 \mathrm{~A}$ \\
DC-side voltage & $200 \mathrm{~V}$ \\
AC-side current & $6 \mathrm{~A}$ \\
AC-side voltage & $110 \mathrm{~V}(\mathrm{RMS})$ \\
\hline
\end{tabular}

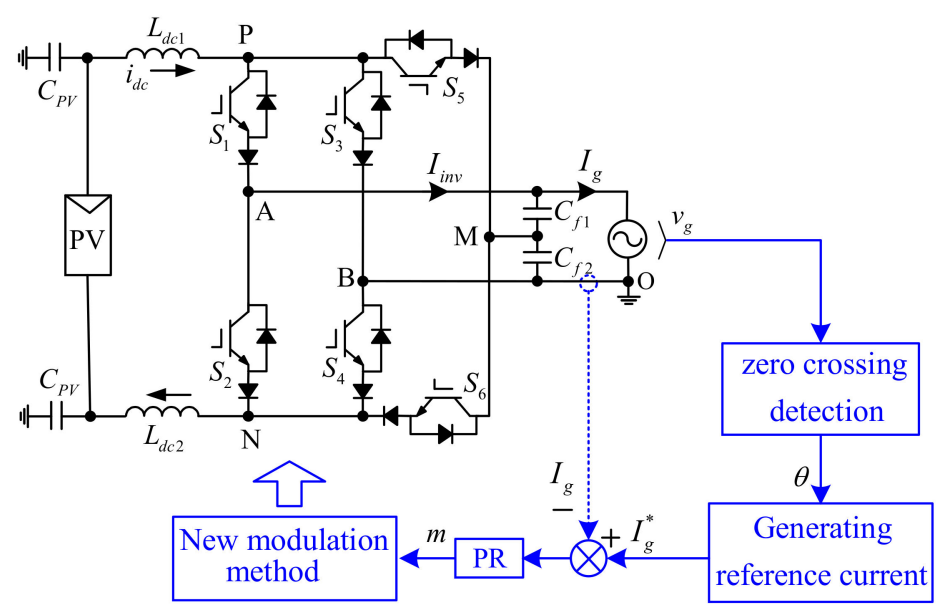

Figure 11. System control block diagram.

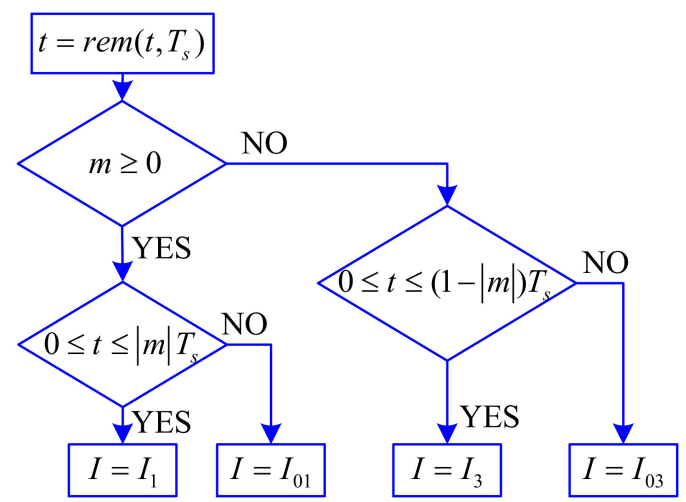

Figure 12. Switching sequence selection for new modulation method.

The experimental results for the conventional current-type inverter are shown in Figure 13. The output current $I_{i n v}$ is unipolar, and the grid current $I_{g}$ is sinusoidal. Figure $13 \mathrm{~b}$ shows the voltages $V_{P O}, V_{N O}$ and the common-mode voltage $V_{C M}$. The leakage current $I_{\text {leakage }}$ waveform is shown in Figure 13c, and the maximum leakage current is $2 \mathrm{~A}$. The switching-frequency variation of the common-mode voltage causes the leakage current to far exceed the $300 \mathrm{~mA}$. As shown in Figure 13d, for the gating signal waveforms of the switches $S_{1}-S_{4}$, the switch $S_{1}$ and the switch $S_{3}$ operate at the power frequency, and the switch $S_{2}$ and the switch $S_{4}$ operate at a high frequency. 


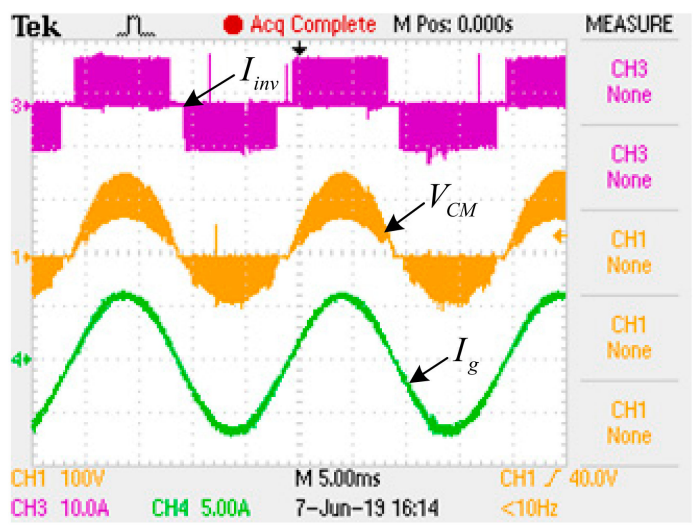

(a)

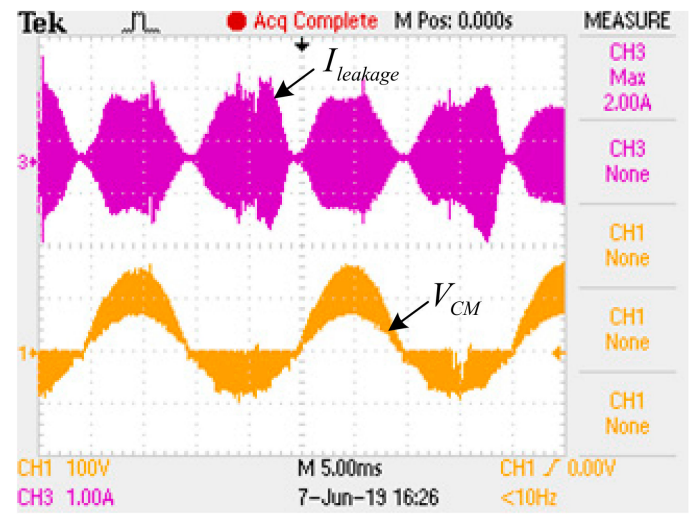

(c)

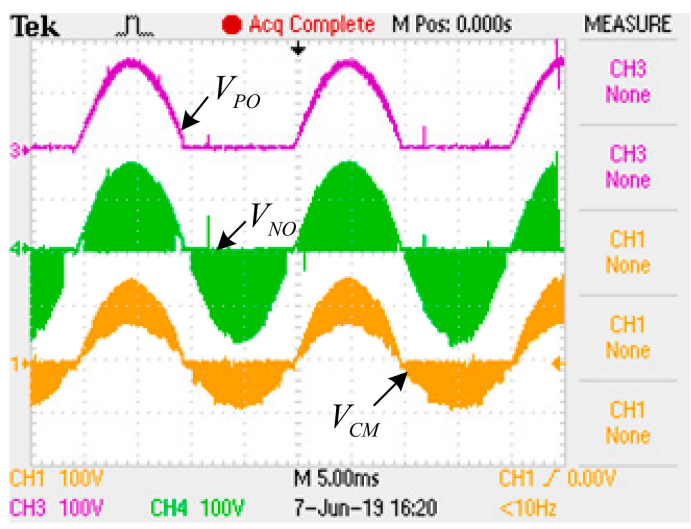

(b)

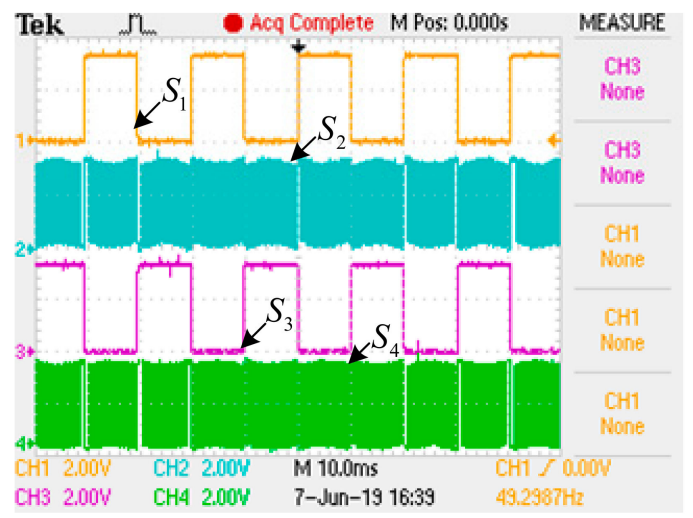

(d)

Figure 13. Results with conventional current-type inverter. (a) Output current $I_{\text {inv }}$, common-mode voltage $V_{C M}$, grid current $I_{g} ;$ (b) $V_{P O}, V_{N O}$, common-mode voltage $V_{C M}$; (c) Leakage current $I_{\text {leakage, }}$ common-mode voltage $V_{C M} ;$ (d) Switches $S_{1}-S_{4}$ gating signal waveforms.

The output current $I_{i n v}$ and the grid current $I_{g}$ are shown in Figure 14a. From Figure 14d, the switches $S_{1}-S_{4}$ operate in power frequency, which reduces the switching loss. Figure 14b is the experimental result of the voltages $V_{P O}, V_{N O}$ and the common-mode voltage $V_{C M}$. The common-mode voltage is the half-grid voltage, ignoring the effect of the fundamental-frequency component of the common-mode voltage on the high-frequency common-mode behavior. According to Equation (5), the leakage current is able to be attenuated. The experimental waveform of the leakage current $I_{\text {leakage }}$ is shown in Figure 14c. The maximum value of the leakage current is $144 \mathrm{~mA}$, which meets the standard and is less than $300 \mathrm{~mA}$, which is satisfactory in terms of the VDE-0126-1-1. 


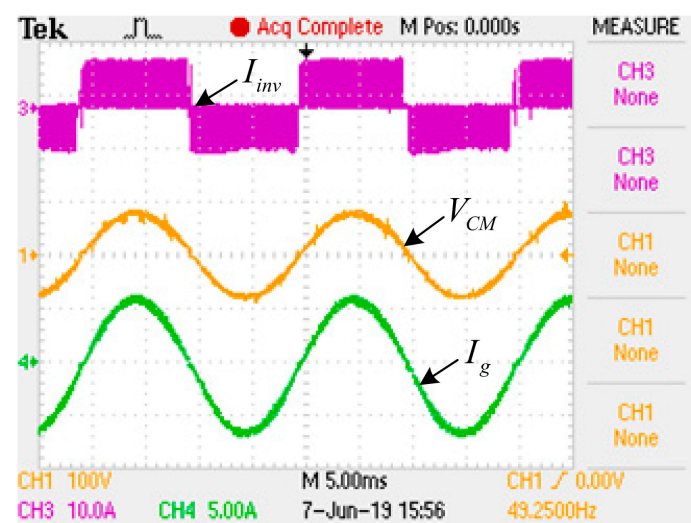

(a)

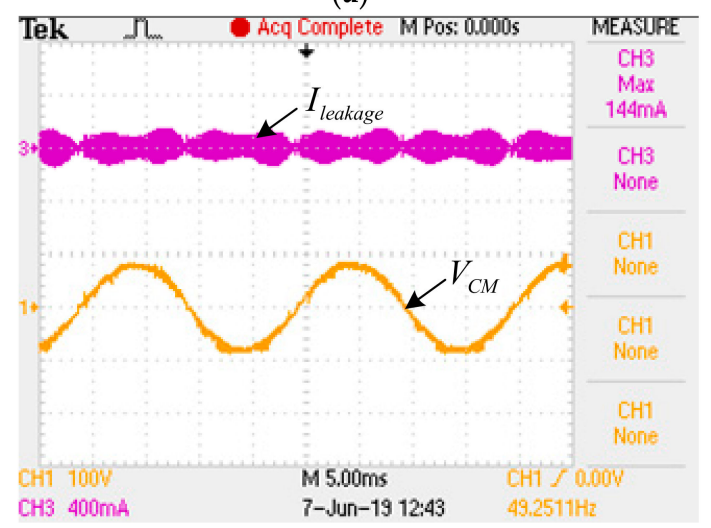

(c)

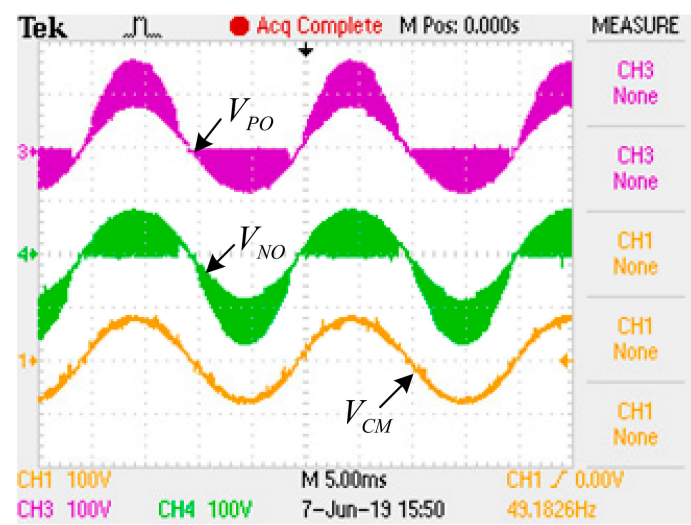

(b)

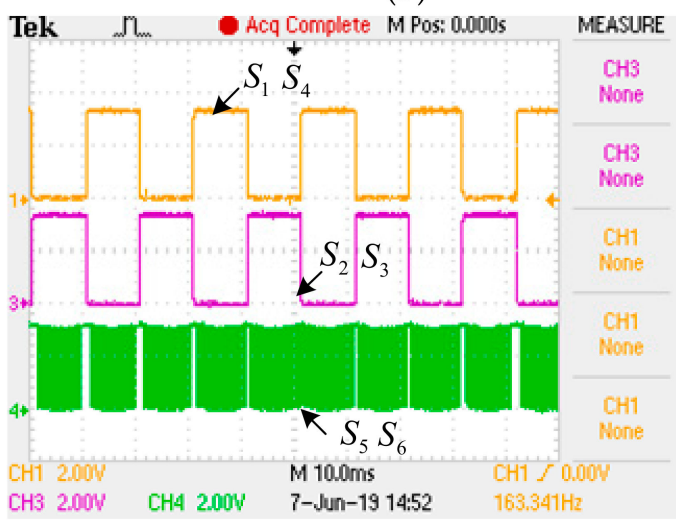

(d)

Figure 14. Results with new current-source inverter. (a) Output current $I_{\text {inv }}$, common-mode voltage $V_{C M}$, grid current $I_{g}$; (b) $V_{P O}, V_{N O}$, common-mode voltage $V_{C M}$; (c) Leakage current $I_{\text {leakage, }}$, common-mode voltage $V_{C M} ;\left(\right.$ d) Switches $S_{1}-S_{6}$ gating signal waveforms.

\section{Conclusions}

In this paper, a novel current-source inverter was proposed. Through the principle analysis and experimental research, the following conclusions were drawn. (1) The high-frequency variation of the common-mode voltage of the conventional current-source inverter cannot effectively suppress the leakage current. (2) The topology proposed in this paper can effectively eliminate the high-frequency common-mode voltage of the system, thus effectively suppressing the system leakage current and satisfying the VDE-0126-1-1 standard.

Author Contributions: This paper was a collaborative effort among each of authors.

Funding: This work was supported in part by the Natural Science Foundation of Hebei Province (E2019203563), and the State Key Laboratory of Reliability and Intelligence of Electrical Equipment (EERIKF2018002), Hebei University of Technology.

Conflicts of Interest: The authors declare no conflict of interest.

\section{References}

1. Xiao, G.; Yang, Y.; He, R.; Wang, B.; Blaabjerg, F. Transformerless Z-source four-leg PV inverter with leakage current reduction. IEEE Trans. Power Electron. 2019, 34, 4343-4352.

2. Ji, Y.; Yang, Y.; Zhou, J.; Ding, H.; Guo, X.; Padmanaban, S. Control strategies of mitigating dead-time effect on power converters: An overview. Electronics 2019, 8, 196. [CrossRef]

3. Siwakoti, Y.P.; Blaabjerg, F. Common-ground-type transformerless inverters for single-phase solar photovoltaic systems. IEEE Trans. Ind. Electron. 2018, 65, 2100-2111. [CrossRef] 
4. Rojas, C.A.; Aguirre, M.; Kouro, S.; Geyer, T.; Gutierrez, E. Leakage current mitigation in photovoltaic string inverter using predictive control with fixed average switching frequency. IEEE Trans. Ind. Electron. 2017, 64, 9344-9354. [CrossRef]

5. Freddy, T.K.S.; Rahim, N.A.; Hew, W.; Che, H.S. Comparison and analysis of single-phase transformerless grid-connected PV inverters. IEEE Trans. Power Electron. 2014, 29, 5358-5369. [CrossRef]

6. Zeng, H.; Li, Y.; Zhang, B.; Zheng, T.Q.; Hao, R.; Yang, Z. An improved H5 topology with low common-mode current for transformerless PV grid-connected inverter. IEEE Trans. Power Electron. 2019, 34, 1254-1265.

7. Kafle, Y.R.; Town, G.E.; Guochun, X.; Gautam, S. Performance comparison of single-phase transformerless PV inverter systems. In Proceedings of the 2017 IEEE Applied Power Electronics Conference and Exposition (APEC), Tampa, FL, USA, 26-30 March 2017.

8. Xiao, G.; Jia, X. Hardware-based cascaded topology and modulation strategy with leakage current reduction for transformerless PV systems. IEEE Trans. Ind. Electron. 2016, 62, 7823-7832.

9. Yang, B.; Li, W.; Gu, Y.; Cui, W.; He, X. Improved transformerless inverter with common-mode leakage current elimination for a photovoltaic grid-connected power system. IEEE Trans. Power Electron. 2012, 27, 752-762. [CrossRef]

10. Guo, X.; Yang, Y.; Zhu, T. ESI: A novel three-phase inverter with leakage current attenuation for transformerless PV systems. IEEE Trans. Ind. Electron. 2018, 65, 2967-2974. [CrossRef]

11. Zhang, L.; Sun, K.; Xing, Y.; Xing, M. H6 transformerless full-bridge PV grid-tied inverters. IEEE Trans. Power Electron. 2014, 29, 1229-1238. [CrossRef]

12. Dai, H.; Jahns, T.; Torres, R.; Han, D.; Sarlioglu, B. Comparative evaluation of conducted common-mode EMI in voltage-source and current-source inverters using wide-bandgap switches. In Proceedings of the IEEE Transportation Electrification Conference and Expo, Long Beach, CA, USA, 13-15 June 2018.

13. Dai, H.; Jahns, T.M. Comparative investigation of PWM current source inverters for future machine drives using high-frequency wide-bandgap power switches. In Proceedings of the IEEE Applied Power Electronics Conference, San Antonio, TX, USA, 4-8 March 2018.

14. Dai, H.; Jahns, T.; Torres, R.; Liu, M.; Sarlioglu, B.; Chang, S. Development of high-frequency WBG power modules with reverse-voltage-blocking capability for an integrated motor drive using a current-source inverter. In Proceedings of the IEEE Energy Conversion Congress and Exposition, Portland, OR, USA, 23-27 September 2018.

15. Torres, R.A.; Dai, H.; Lee, W.; Jahns, T.M.; Sarlioglu, B. Current-source inverters for integrated motor drives using wide-bandgap power switches. In Proceedings of the 2018 IEEE Transportation Electrification Conference and Expo, Long Beach, CA, USA, 13-15 June 2018.

16. Chen, Y.; Smedley, K. Three-phase boost-type grid-connected inverter. IEEE Trans. Power Electron. 2008, 23, 2301-2309. [CrossRef]

17. Dash, P.P.; Kazerani, M. Dynamic modeling and performance analysis of a grid-connected current-source inverter-based photovoltaic system. IEEE Trans. Sustain. Energy 2011, 2, 443-450. [CrossRef]

18. Wang, Z.; Zou, Z.; Zheng, Y. Design and control of a photovoltaic energy and SMES hybrid system with current-source grid inverter. IEEE Trans. Appl. Supercond. 2013, 23, 5701505. [CrossRef]

19. Anand, S.; Gundlapalli, S.K.; Fernandes, B.G. Transformer-less grid feeding current source inverter for solar photovoltaic system. IEEE Trans. Ind. Electron. 2014, 61, 5334-5344. [CrossRef]

20. Barbosa, G.; Braga, C.; Rodrigues, B.; Teixeira, E. Boost current multilevel inverter and its application on single-phase grid-connected photovoltaic systems. IEEE Trans. Power Electron. 2006, 21, 1116-1124. [CrossRef]

21. Noguchi, T. A new three-level current source PWM inverter and its application for grid connected power conditioner. Energy Convers. Manag. 2010, 51, 1491-1499.

22. Garcia, L.S.; Buiatt, G.M.; de Freitas, L.C.; Coelho, E.; Farias, V.J.; de Freitas, L.C.G. Dual transformerless single-stage current source inverter with energy management control strategy. IEEE Trans. Power Electron. 2013, 28, 4644-4656. [CrossRef]

23. Gonzalez, R.; Lopez, J.; Sanchis, P.; Marroyo, L. Transformerless inverter for single-phase photovoltaic systems. IEEE Trans. Power Electron. 2007, 22, 693-697. [CrossRef]

(C) 2019 by the authors. Licensee MDPI, Basel, Switzerland. This article is an open access article distributed under the terms and conditions of the Creative Commons Attribution (CC BY) license (http://creativecommons.org/licenses/by/4.0/). 